\title{
Nuclear Posture and Technology Trends in South Asia and Ways Ahead
}

\author{
Author: Stefanovich, Dmitry
}

To cite this article: Stefanovich, D. (2022). Nuclear Posture and Technology Trends in South Asia and Ways Ahead. National Security Journal. Published 01 March 2022. doi:10.36878/nsj20220301.11

To link to this article: https://doi.org/10.36878/nsj20220301.11

View CrossRef data: https://search.crossref.org/?q=10.36878\%2Fnsj20220301.11 


\title{
NUCLEAR POSTURE AND TECHNOLOGY TRENDS IN SOUTH ASIA AND WAYS AHEAD
}

\author{
Dmitry Stefanovich ${ }^{1}$
}

\begin{abstract}
The dynamics of nuclear posture and weapons technology development in South Asia are diverse and rapidly shifting. Without real measures to manage these, the situation can spiral out of control. Threat perceptions and misperceptions among the leadership of South Asian nuclear weapon states affect doctrinal and force posture shifts in the nuclear domain. Moreover, third parties play an increasingly important role in these dynamics. There is an impetus for creating and implementing risk reduction and arms control measures to address these various factors and their impact on nuclear posture and technology development.
\end{abstract}

Key Words: South Asia, nuclear weapons, strategic stability, arms control, nuclear proliferation, emerging technologies

\section{Introduction}

In the broadest sense, South Asia is often considered a focal point of numerous nuclear weapons-related challenges that suggest the potential for nuclear use. ${ }^{1}$ This assessment is based on three key factors. First, the region is marked by bilateral nuclear deterrence between India and Pakistan, which is affected by various third parties. Second, the region is beset by 'frozen' conflicts and territorial disputes, including those involving non-state actors. Third, the region is impacted by the general degradation of global and regional security in the $21^{\text {st }}$ century. In light of these factors, this essay will explore nuclear posture and technology trends to offer some suggestions of first steps towards finding solutions in South Asia, including recommendations based on experiences from other parts of the world.

$1 \quad$ Mr Stefanovich is a Research Fellow in the Primakov National Research Institute of World Economy and International Relations of the Russian Academy of Sciences (IMEMO RAS). 


\section{Nuclear Postures and Technologies}

Understanding the intersection between nuclear posture and technologies is essential to formulating a framework for addressing nuclear weapons-related challenges. There are five noteworthy diverging and converging postural and technological trends that are central to the South Asia region. Among nuclear postures, the first is no first use (NFU), which is currently the declaratory policy of India and China, yet hardly an option for Pakistan. The second is tailored deterrence, which allows countries in the region to address different perceived threats. The third is escalate-to-de-escalate, which may be viewed as either a 'mythical concept' or a universally accepted way of achieving the 'higher ground' in a conflict. ${ }^{2}$ Among technologies, the first is early warning capabilities, which can provide for a switch to launch-on-warning (LOW) doctrine posture and assorted force multipliers. The second includes enhanced non-nuclear strike capabilities, which are augmented by advances in intelligence, surveillance and reconnaissance (ISR) assets, space, counter-space and cyber capabilities. This ever-increasing complexity of variables that affect the nuclear domain is a global trend. As such, nuclear risk reduction and arms control can and should be a multilateral effort. ${ }^{3}$ However, since this essay focuses on nuclear challenges that are present and pressing for South Asia, it makes sense to focus on the region in question for ways ahead.

\section{No First Use and Tailored Deterrence}

Among the more pertinent concepts that require greater attention and analysis is that of NFU. In its most basic form, this posture may be defined as a declaration of intent not to be the first to use nuclear weapons in an armed conflict. ${ }^{4}$ While NFU is present in the declaratory statements of both India and China, there are differences between the two countries' pledges. ${ }^{5}$ These differences include the nature of both their capabilities and declaratory policies. In terms of the declaratory policy, Indian experts like Brahma Chellaney have argued that China introduced a 'condition' clause in 1995, limiting NFU to states parties to the Treaty on the Non-Proliferation of Nuclear Weapons (NPT). ${ }^{6}$ However, this clause no longer appears in official Chinese statements. ${ }^{7}$

Similarly, experts from Pakistan have pointed to India's biological and chemical weapons caveats and debates surrounding its NFU pledge. ${ }^{8}$ These caveats point to one of the largest challenges in maintaining the credibility of such declarations. To be considered credible, the composition of nuclear forces, operational practices, nuclear command, control and communications (NC3) systems must all follow a single pattern. In other words, nuclear posture should be tailored to one and only mission: survivable and credible second strike. However, as no country is the same and all exist in a diverse and competitive environment, actions and developments considered compatible with the NFU declaration of one country may be totally incompatible by another. 
Currently, a major similarity between China's and India's nuclear postures resides in their development of nuclear forces that emphasise robust multi-domain capabilities. Both countries are moving towards a classic strategic nuclear triad of land-, sea- and air-based nuclear weapon delivery systems. Both are developing advanced land-based ballistic missiles of different ranges, as with China's Dongfeng series and India's Agni series. ${ }^{9}$ Both are also working to deploy ballistic missile submarines (SSBNs) with nuclear propulsion, as with China's Type 094A SSBN and India’s S4 SSBN..$^{10}$ Further, each country continues to upgrade its air-delivery platforms, as with China's Xian H-20 subsonic stealth bomber and India's potential application of the nuclear-capable Rafale Dassault multirole fighter aircraft. Finally, both are pursuing hypersonic weapons, as with China's DF-17 medium-range ballistic missile mounted with the DF-ZF hypersonic glide vehicle (HGV) and Xingkong-2 hypersonic flight vehicle, and India's Hypersonic Technology Demonstrator Vehicle (HSTDV) and Shaurya hypersonic surface-tosurface tactical missile. ${ }^{11}$

Despite this convergence of pursuits, there are notable qualitative and quantitative differences. For instance, China is more focused on developing and fielding both regional and intercontinental range systems, with growing emphasis on the latter due to deteriorating relations with the United States. ${ }^{12}$ By contrast, India finds regional and even sub-regional capabilities to be of greater importance. Nevertheless, China's and India's varied delivery options highlight a 'traditional approach' of maintaining nuclear survivability with a strategic triad. Under this strategy, both seek deployment of multiple platforms across different domains that are capable of surviving strikes by an adversary and delivering a decisive counterattack.

Simultaneously, the priority of enhancing survivability through various delivery platforms suggests that China and India may be trending towards more nuanced and tailored nuclear use options, which to some extent might be perceived as contradicting their NFU pledges. As just one example, reports of China's development of early warning capabilities negatively affect its NFU pledge's credibility, as such advances suggest an ability to shift towards a LOW posture..$^{13}$ This is because it is believed that a survivable nuclear deterrent tailored for NFU policy does not need an advance warning of incoming missiles. Still, there are some stabilising effects of enhanced early warning, since it would improve the situational awareness of Chinese leadership, potentially contributing to the de-escalation of crises. Suppose a decision-maker is confident in his understanding of the crisis dynamics, including the moment when a 'war of nerves' turns into a 'shooting war'. In that case, he might be less eager to press the proverbial red button prematurely. Moreover, early warning capabilities may provide a better understanding of targets for adversary strikes should those be launched.

As with the qualified convergences above in Chinese and Indian nuclear posture, there are some stark divergences. Primary among these is the fact that while India engages in regional deterrence vis-à-vis Pakistan and China, China must maintain a nuclear 
deterrent against the United States. This means that China's capabilities are essentially global in scale, effectively capable of carrying out strikes against any target on the planet. When combined with the necessity of taking India into account, China must have a multi-pronged deterrent that addresses both regional and extra-regional contingencies. Thus, even though their deterrents possess a different reach and aim, both China and India may be compelled to maintain a tailored nuclear posture that engages in varied approaches to confront their potential adversaries.

\section{Escalate to De-escalate and Force Multipliers}

In recent years, the concept of escalate to de-escalate has become a focal point for analysts and decision-makers. This posture provides for early and limited use of nuclear weapons in conflict to achieve an escalation dominance so that the adversary would back down. ${ }^{14}$ Theoretically, such a posture might exist, but it is hardly possible under real-world conditions. This is because the likelihood of retaliation would be too great for a political decision-maker or military commander to undertake such a limited nuclear strike, and such retaliation would most probably be nuclear. Still, for countries that are engaged in regional warfighting and the misperceptions inherent among regional leadership, there remains the potential for nuclear escalation and even limited use with, though with grave consequences. ${ }^{15}$

In the cases of both Russia and Pakistan, which some have compared in terms of their potential for escalate to de-escalate policies, ${ }^{16}$ both face a strategic environment of relative conventional inferiority to their potential adversaries in quantitative-overwhelming numbers-and qualitative-superior technology-terms. As a result, nuclear weapons take on the role of force multipliers. In other words, one nuclear-armed system can offset a number of non-nuclear systems due to greater destructive power and decreased precision requirements. While some may posit that a limited nuclear war may be preferable to a global one, there remain significant questions as to whether the scale of the former can be controlled in such regions as South Asia. ${ }^{17}$ Further, on a more global scale, while some recent editions of official US documents provide that nuclear use may restore strategic stability, in Russia's case the very concept of 'deterrence' is no longer applicable once nuclear weapons have been used. ${ }^{18}$ Nuclear weapon use creates a totally different environment and dynamics, precluding 'pre-nuclear' dynamics.

\section{Counterforce and Technological Advances}

Beyond nuclear posture, major changes may be related to the advance of counterforce capabilities, which enable the targeting of an opponent's military infrastructure with a nuclear strike. The pursuit of counterforce capabilities may be seen as largely due to a threat spectrum for countries that is marked by ever-increasing precision, speed and stealth. ${ }^{19}$ Suppose one party is able to utilise these three elements to disarm or decapitate its adversary, or at least to undermine their nuclear command, control and 
communications (NC3) and early warning systems. In that case, this can rapidly lead to instability. Thus, not surprisingly, the debate over counterforce trends in South Asia has gained momentum.

Among the platforms that are contributing to this debate are India's Brahmos supersonic cruise missiles, including air-launched versions, which may eventually provide a rather substantial counterforce capability. ${ }^{20}$ This is because of their supersonic speed, high precision and lethality against assorted targets, as well as their potential for deployment on multiple platforms to hold adversary targets at risk. Nonetheless, Brahmos is currently a platform with a conventional payload and relatively short-range, including the possible $800 \mathrm{~km}$ upgrade, thereby limiting its truly strategic effects. ${ }^{21}$

Further, counterforce may be strengthened through land-attack cruise missiles of different air-, sea- and land-basing modes, which are extremely hard to protect against and can be launched in massive salvos. The examples of relevant weapon systems are the Pakistani Babur/Hatf-VII ground-launched cruise missile and its Harbah sea-launched variant, ${ }^{22}$ as well as India's Nirbhay cruise missile that has ground-launched, air-launched and sea-launched variants. ${ }^{23}$ Additionally, the fielding of submarine-launched ballistic missiles (SLBMs) within South Asia is destined to improve in range and precision, countering traditional narratives of their utility only in countervalue missions. Actually, in the case of India, its Sagarika/Shaurya SLBM development project is marked by precision, even though it still lacks in range. ${ }^{24}$

India and Pakistan may also be pursuing multiple independently targetable re-entry vehicles (MIRVs). ${ }^{25}$ If it comes to fruition, this development would multiply the number of targets that can be hit with a single missile, causing a profound impact on nuclear deterrence in South Asia. At one level, this is because dramatically more targets will be held at risk with a given number of missiles. On another level, the introduction of MIRVed systems will also increase the retaliatory capability, even if only a limited number of weapons survive a disarming strike. As a result, this would increase second-strike capability and have a stabilising effect.

Furthermore, the development of manoeuvrable re-entry vehicles (MaRV), and HGV as their most sophisticated version, could dramatically increase the single-shot kill probability against high-priority targets. This is due to their higher precision and missile defense evasion and penetration capability. While India has demonstrated an interest in HGV development, this may be more important for its position as a global power, than for its regional deterrence purposes. ${ }^{26}$ Nevertheless, if India proceeds, Pakistan will most definitely consider HGVs in its own military planning and threat assessments.

Finally, while missile defences in general currently remain unreliable, costly and practically non-existent in the region, their capabilities are likely to improve over time. ${ }^{27}$ This view is particularly relevant among those countries that feel threatened by such capabil- 
ities. This interaction of capability and threat perception will result in greater instability, particularly when matched with the aforementioned disarming and decapitation capabilities. This is of particular relevance in South Asia given that Indian missile defence capabilities may dramatically increase over the next decade with the introduction of the Russian-made S-400 air and missile defence system. ${ }^{28}$

While the S-400 might be considered primarily as an instrument against aerodynamic threats, it also has counter-ballistic capabilities and Pakistan definitely perceives it as capable of affecting regional balance. ${ }^{29}$ Within Pakistan's threat calculus, this also portends the potential future introduction of a more capable S-500, combined with the development of indigenous anti-satellite technologies closely linked to missile defence interceptor development. ${ }^{30}$ While the prospective of a capable multi-layered missile defence system for India remains vague, the efforts are underway and cannot be dismissed, particularly for their impact on Pakistan's threat perceptions. ${ }^{31}$

In the face of these technological advances, which in many cases favour India, Pakistan has also been compelled to invest in new capabilities, such as the P282 ballistic missile, which is said to be capable of both anti-ship and land-attack missions. While it purportedly is capable of hypersonic speeds, its endo-atmospheric manoeuvrability, which is a must for 'hypersonic missiles', remains to be seen. ${ }^{32}$ As it seeks to harden its launch positions and develop penetration aids, Pakistan is likely to focus on the very same capabilities for deterrence forces as Russia, in other words those that are both survivable and deliverable. These include decoys, road-mobile launchers supported by concealment vehicles, broadened patrol areas and increased readiness. And given Pakistan's strong relations with China, solutions developed for the People's Liberation Army Rocket Forces may be implemented in Pakistan. ${ }^{33}$

\section{Charting Ways Ahead}

Facing the above complexity of nuclear postures and technologies, there is a menu of options or starting points that can contribute to mitigating and addressing nuclear challenges in South Asia. While the following is not an exhaustive list, it highlights some useful recommendations for the region. ${ }^{34}$

\section{Escalation and De-escalation}

While recognising the inherent sensitivities of joint research, there may be room for Indian and Pakistani nuclear experts to explore the experiences of other nuclear powers for best practices. This could be useful in avoiding some of the deleterious arms racing and trends that have occurred between such nuclear powers as the United States and Russia. This joint project could even include Chinese scholars. Whether in a bilateral or trilateral format, a joint project would facilitate an understanding of escalation triggers and de-escalation measures. 


\section{Strategic Impact of Non-nuclear Capabilities}

Given the range of non-nuclear capabilities being developed within South Asia, a joint study that includes Indian and Pakistani experts could also be conducted to understand better how these technological trends affect nuclear posture and nuclear deterrence. As one example, such studies could address the impact of surgical strikes by non-nuclear high-precision weapons on nuclear forces and NC3. While such studies may not lead to a common view, they will contribute to better mutual understanding and identification of strategic stability factors.

\section{Risk Reduction and Arms Control Measures ${ }^{35}$}

Building upon the joint studies above, in the longer term there may be room for further risk reduction and specifically arms control measures in South Asia. These could be undertaken in a series of steps:

1) declaration of capabilities and doctrines to address the mutual misperceptions;

2) unilateral or joint introduction of transparency and confidence-building measures with regard to development programs and deployment patterns;

3) agreement on restrictions and limitations of selected weapon systems considered to be especially destabilising;

4) physical and operation reductions that could begin with militarily less relevant systems, such as obsolete short-range ballistic missile systems or tactical aircraft for delivery of nuclear gravity bombs; and

5) verification.

Recognising the unique complexities within South Asia, such steps may be a distant possibility. However, establishing a basic framework and series of steps, which build upon the findings of joint studies on the experiences of other nuclear powers, could provide a starting point.

\section{Conclusion}

With the increasingly complicated architecture of nuclear postures and technologies in South Asia, it is increasingly difficult to ensure nuclear deterrence and to prevent escalation. At the same time, there are stabilising spin-off effects in that the growing number of variables complicates planning for a decisive strike against an adversary. Indian investments in strategic military capabilities can be considered the main factor in a regional balance. Such developments will affect both India-Pakistan and India-China strategic balance, with limited destabilising effects for the former dyad and stabilising effects for the latter. 
In the case of the India-Pakistan dyad, any investment in sophisticated military capabilities will be considered as a push to gain a military edge. It could result in immediate countermeasures and fuel an arms race. Overall, this would adversely impact threat perceptions, effectively unnerving the decision-makers on the opposing side. However, as there are no capabilities that might change the balance dramatically on the horizon, such effects will be limited in nature. On the China-India dyad, increased Indian capabilities might lead to more balanced military-political relations. Yet they may also affect Chinese planning and force posture in order to adequately address both Indian and US threats, resulting in a potentially adverse centripetal force within the Indo-Pacific region.

There are no easy steps that can rapidly achieve stabilisation of military-political relations and prevent escalation in any region of the world. Current global dynamics hardly offer any room for optimism. Nevertheless, given the experience of addressing military and specifically nuclear weapons-related challenges in many other periods of history and groupings of competing nations, it may be possible to find some viable precedents. Establishing joint studies is one way to find applicable lessons learned. It is certainly not evident that the leadership in South Asia seeks to engage in a nuclear showdown, much as it is not the case in other parts of the world. Thus, the expert community should continue to seek transparency and confidence-building measures through joint efforts and hope that there will be enough political will to implement these ways ahead.

1 For one example, please see: Robock, Alan; Toon, Owen B.; Bardeen, Charles G.; Xia, Lili; Kristensen, Hans M.; McKinzie, Matthew; Peterson, R.J.; Harrison, Cheryl S.; Lovenduski, Nicole S.; and Turco, Richard P., 'How an India-Pakistan nuclear war could start-and have global consequences', Bulletin of the Atomic Scientists, vol. 75, no. 6, pp. 273-279.

2 Khan, Feroz Hassan, 'Russia-Pakistan Strategic Relations: An Emerging Entente Cordiale', Air University, 15 Jan. 2021, <https://www.airuniversity.af.edu/JIPA/Display/Article/2473361/russiapakistan-strategic-relations-an-emerging-entente-cordiale>.; Oliker, Olga and Baklitskiy, Andrey, 'The Nuclear Posture Review and Russian "De-escalation”: A Dangerous Solution to a Nonexistent Problem', War on the Rocks, 20 Feb. 2018, <https://warontherocks.com/2018/02/nuclear-posture-review-russian-de-escalation-dangerous-solution-nonexistent-problem $>$; Krepon, Michael, 'Escalating to Deescalate', Arms Control Wonk, 28 Feb. 2018, <https://www.armscontrolwonk.com/archive/1204755/escalating-to-de-escalate $>$.

3 The following is a quote from Russian President Vladimir Putin: 'There are other nuclear states that are not officially recognised as such, as it were, but the whole world knows that they have nuclear arms. So, are we going to behave like ostriches? Hide our heads in the sand and pretend that we do not understand what is going on? What we need is not a checkerboard pattern on our car. We need to drive it; therefore, we need to ensure security. So, let us get them involved as well. Let us do it. We are not against this'. President of Russia, 'Meeting of the Valdai Discussion Club', Russian Federation, 22 October 2020, http://en.kremlin.ru/events/president/news/64261

4 Global Zero, 'No First Use FAQs', <https://www.globalzero.org/no-first-use-faqs>, accessed on 15 Oct. 2021.

5 Pan, Zhenqiang, 'A Study of China's No-First-Use Policy on Nuclear Weapons', Journal for Peace and Nuclear Disarmament, vol. 1, no. 1, 2018, pp. 115-136; Dalton, Toby, 'Much ado about India's 
no-first-use nuke policy', India Global Business, 26 Sep. 2019, <https://www.indiaglobalbusiness.com/ igb-archive/much-ado-about-indias-no-first-use-nuke-policy>.

6 Brahma Chellaney, 'The India-Pakistan-China Stategic Triangle and the Role of Nuclear Weapons', IFRI Proliferation Papers, Winter 2002, <https://inis.iaea.org/collection/NCLCollectionStore/_Public/37/066/37066507.pdf>.

7 Preparatory Committee for the 2020 Review Conference of the Parties to the Treaty on the Non-Proliferation of Nuclear Weapons, 'Implementation of the Treaty on the Non-Proliferation of Nuclear Weapons in the People's Republic of China', NPT/CONF.2020/PC.III/8, 29 Apr. 2019, <https://documents-dds-ny.un.org/doc/UNDOC/GEN/N19/124/15/PDF/N1912415.pdf?OpenElement>.

8 See the essay in this volume by Adil Sultan.

9 Missile Threat, 'Missiles of China', 12 Apr. 2021, <https://missilethreat.csis.org/country/china>; Chattopadhyay, Deepan, 'Missiles Of India - A Comprehensive Overview Of India's Deadly Missile Arsenal', RepublicWorld.com 24 Sep. 2021, <https://www.republicworld.com/india-news/general-news/ missiles-of-india-a-comprehensive-overview-of-indias-deadly-missile-arsenal.html>.

10 Center for Strategic and International Studies, 'A Glimpse of Chinese Ballistic Missile Submarines', 4 Aug. 2021, <https://www.csis.org/analysis/glimpse-chinese-ballistic-missile-submarines>; Unnithan, Sandeep, 'From India Today magazine: A peek into India's top secret and costliest defence project, nuclear submarines', India Today, 10 Dec. 2017, <https://www.indiatoday.in/magazine/the-big-story/ story/20171218-india-ballistic-missile-submarine-k-6-submarine-launched-drdo-1102085-2017-12-10>.

11 Bernstein, Paul and Hancock, Dain, 'China's Hypersonic Weapons', Georgetown Journal of International Affairs, 27 Jan. 2021, <https://gjia.georgetown.edu/2021/01/27/chinas-hypersonic-weapons >; Simha, Rakesh Krishnan, 'Hypersonic Weapons: Why India Must Close the Technology Gap', Raksha Anirveda, 17 Sep. 2020, <https://www.raksha-anirveda.com/hypersonic-weapons-why-india-must-close-the-technology-gap $>$.

12 Wright, Timothy, 'Is China gliding toward a FOBS capability?', International Institute of Strategic Studies, 22 Oct. 2021, <https://www.iiss.org/blogs/analysis/2021/10/is-china-gliding-toward-a-fobscapability>.

13 Stefanovich, Dmitry, 'Russia to Help China Develop an Early Warning System', The Diplomat, 25 Oct. 2019, <https://thediplomat.com/2019/10/russia-to-help-china-develop-an-early-warning-system>.

14 Oliker, Olga and Baklitskiy, Andrey, 'The Nuclear Posture Review and Russian "De-escalation": A Dangerous Solution to a Nonexistent Problem', War on the Rocks, 20 Feb. 2018, <https://warontherocks. com/2018/02/nuclear-posture-review-russian-de-escalation-dangerous-solution-nonexistent-problem>.

15 Raghavan, V. R. 'Limited war and nuclear escalation in South Asia', The Nonproliferation Review, vol. 8, no. 3, 2001, pp. 82-98, <https://www.nonproliferation.org/wp-content/uploads/npr/83ragh.pdf>.

16 Saalman, Lora and Topychkanov, Petr, 'South Asia's Nuclear Challenges: Interlocking Views from India, Pakistan, China, Russia and the United States', Stockholm International Peace Research Institute, April 2021, <https://www.sipri.org/sites/default/files/2021-03/2104_south_asias_nuclear_challenges_0. pdf>.

17 Robock, Alan; Toon, Owen B.; Bardeen, Charles G.; Xia, Lili; Kristensen, Hans M.; McKinzie, Matthew; Peterson, R.J.; Harrison, Cheryl S.; Lovenduski, Nicole S.; and Turco, Richard P., 'How an India-Pakistan nuclear war could start — and have global consequences', Bulletin of the Atomic Scientists, vol. 75 , no. 6 , pp. $273-279$.

18 Please see the following citation. However, please note that an updated version of this document uses slightly less provocative language. Joint Force Development, 'Nuclear Operations', Joint Publication, 3-72, 11 Jun. 2019, <https://fas.org/irp/doddir/dod/jp3 72.pdf>; Ministry of Foreign Affairs, 'Basic Principles of State Policy of the Russian Federation on Nuclear Deterrence', Russian Federation, 8 Jun. 2020, p. 11, <https://www.mid.ru/en/web/guest/foreign_policy/international_safety/disarmament/-/asset_publisher/rp0fiUBmANaH/content/id/4152094>.

19 Schneider, Barry R., 'Counterforce targeting capabilities and challenges', US Air Force Counterproliferation Center Future Warfare Series, No. 22, Aug. 2004, <https://media.defense.gov/2019/ Apr/11/2002115487/-1/-1/0/22COUNTERFORCETARGETING.PDF>.

20 Clary, Christopher and Narang, Vipin, 'India's Counterforce Temptations: Strategic Dilemmas, Doctrine, and Capabilities', International Security, vol. 43, no. 3, Winter 2018/19, pp. 7-52, <https://direct. mit.edu/isec/article/43/3/7/12216/India-s-Counterforce-Temptations-Strategic $>$.

21 'Russia, India to extend BrahMos supersonic missile's range to 800 km', TASS, 20 Jul. 2021, $<$ https://tass.com/defense/1315847>. 
22 Missile Defense Project, 'Babur (Hatf 7)', Missile Threat, Center for Strategic and International Studies, 16 Sep. 2016, last modified August 4, 2021, https://missilethreat.csis.org/missile/hatf-7/.

23 Missile Defense Project, 'Nirbhay', Missile Threat, Center for Strategic and International Studies, 11 Aug. 2016, <https://missilethreat.csis.org/missile/nirbhay>.

24 Missile Defense Project, 'Sagarika/Shaurya', Missile Threat, Center for Strategic and International Studies, 11 August 11, 2016, >https://missilethreat.csis.org/missile/sagarika-shaurya>.

25 Kristensen Hans M. and Korda, Matt, 'Indian nuclear forces', Bulletin of the Atomic Scientists, vol. 74, no. 6, pp. 361-366; Kristensen, Hans M.; Norris, Robert S.; and Diamond, Julia, 'Pakistani nuclear forces', Bulletin of the Atomic Scientists, vol. 74, no. 5, pp. 348-358.

26 Sethi, Manpreet, 'Missile developments in Southern Asia: A perspective from India', International Institute for Strategic Studies, 17 Jun. 2021, <https://www.iiss.org/blogs/research-paper/2021/06/missile-developments-southern-asia>.

27 Isaacs, John and Hickey, Samuel M., 'Missile Defense Costs Soar Out of This World', Center for Arms Control and Non-Proliferation, 26 Jan. 2021, <https://armscontrolcenter.org/missile-defense-costssoar-out-of-this-world $>$.

28 Rosoboronexport, 'S-400 "Triumph", <http://roe.ru/eng/catalog/air-defence-systems/air-defensesystems-and-mounts/s-400-triumf>, accessed on 18 Oct. 2021.

29 The News, 'Pakistan strongly reacts to Indian purchase of S-400 missiles', 19 Oct. 2018, <https:// www.thenews.com.pk/latest/382900-pakistan-strongly-reacts-to-indian-purchase-of-s-400-missiles>.

30 TASS, 'Борисов заявил, что Индия потенциально может стать первым покупателем системы C-500' [Borisov said that India could potentially become the first buyer of the S-500 system], 16 Sep. 2021, <https://tass.ru/armiya-i-opk/12420591>; Tellis, Ashley J., 'India's ASAT Test: An Incomplete Success', Carnegie Endowment for International Peace, 15 Apr. 2019, <https://carnegieendowment. org/2019/04/15/india-s-asat-test-incomplete-success-pub-78884>.

31 Shaza, Arif, 'India's Acquisition of the S-400 Air Defense System: Implications and Options for Pakistan', Journal of Indo-Pacific Affairs, 25 Aug. 2021, < https://www.airuniversity.af.edu/JIPA/Display/ Article/2743750/indias-acquisition-of-the-s-400-air-defense-system-implications-and-options-for> .

32 Ali, Samran, 'P282 Anti-ship Ballistic Missile: Strengthening Navy’s Conventional Deterrence', The Centre for Strategic and Contemporary Research, 21 Jun. 2021, <https://cscr.pk/explore/themes/defense-security/p282-anti-ship-ballistic-missile-strengthening-navys-conventional-deterrence>.

33 Dawn, 'Chinese military technology will define Pak response to Indian threat', 14 Feb. 2020, $<$ https://www.dawn.com/news/1534277>.

34 For a more comprehensive analysis, please see Wan, Wilfred (ed.) Nuclear Risk Reduction: Closing Pathways to Use, (Geneva: United Nations Institute for Disarmament Research, 2020), <https://doi. org/10.37559/WMD/20/NRR/01>.

35 The author considers arms control to be a sub-set of a broader risk reduction measures. 